\title{
MODIFICATION OF POLYCYANURATE NETWORKS WITH PROTIC ADDITIVES BASED POLYDIMETHYLSILOXANE
}

\author{
Laurent Barthélémy, Annie Boch, Jean Lafitte, Valérie Mirco, Françoise Méchin * \\ and Jean-Pierre Pascault \\ Laboratoire des Matériaux Macromoléculaires, UMR CNRS n5627, \\ Institut National des Sciences Appliquées de Lyon, Bât. 403 \\ 20, avenue Albert Einstein, 69621 Villeurbanne Cedex, France
}

\begin{abstract}
Hydroxy telechelic polycaprolactone / polydimethylsiloxane I polycaprolactone triblock copolymers were used to modify aromatic polycyanurates networks through a polycondensationinduced phase separation. Model studies revealed that the cyclotrimerization mechanism in the presence of alcohol functions was complex. The additives, which activate the reaction, are finally chemically linked to the matrix. Both thermodynamic and kinetic features result in very finely divided morphologies, with highly interpenetrated phases which contribute to a great improve of the static mechanical properties.
\end{abstract}

Published in Macromolecular Symposia vol. 122, 167-172 (1997) 


\section{INTRODUCTION}

Aromatic dicyanates are the parent monomers for a series of new high-performance networks/ obtained by polycyclotrimerization:<smiles>[R]Oc1nc([R])nc(O[R])n1</smiles>

The resulting polycyanurates display high crosslink density, glass transition temperature and thermal stability, good mechanical properties and low dielectric constants (Ref. 1), which makes them good candidates for microelectronics or structural aerospace applications. However, they are still brittle and often require the addition of small amounts of an oligomeric modifier (elastomer or thermoplastic) to improve their crack-propagation resistance. Protic functions such as phenols, alcohols and amines are susceptible to react with cyanates (Ref. 2) and a former study in our laboratory (Refs. 3,4) already revealed the great influence of modifiers bearing such functions on the network build-up and on the final properties of the material. In this study, the behavior of two aromatic dicyanates in the presence of various amounts of dihydroxytelechelic polycaprolactone (PCL) - polydimethylsiloxane (PDMS) - PCL triblock copolymers is described and compared with the results obtained with a model monofunctional alcohol.

\section{MATERIALS}

4,4'-dicyanato-2,2-diphenylpropane (DCBA, Ciba-Geigy) is a pure crystalline monomer $\left(\mathrm{T}_{\mathrm{m}}=80^{\circ} \mathrm{C}\right)$. On the contrary, 4,4'-dicyanato-1,1 -diphenylethane (DCBE, Ciba-Geigy) is an undercooled liquid at room temperature $\left(T_{m} \approx 35^{\circ} \mathrm{C}\right)$ because of a slight conversion of its cyanate functions $(x \approx 0.03)$. Both were used as received, as well as 2-phenoxy ethanol ( $P_{2} E$, Aldrich). Hydroxy-terminated PCL-b-PDMS-b-PCL block copolymers were obtained from Goldschmidt and display the following general structure:

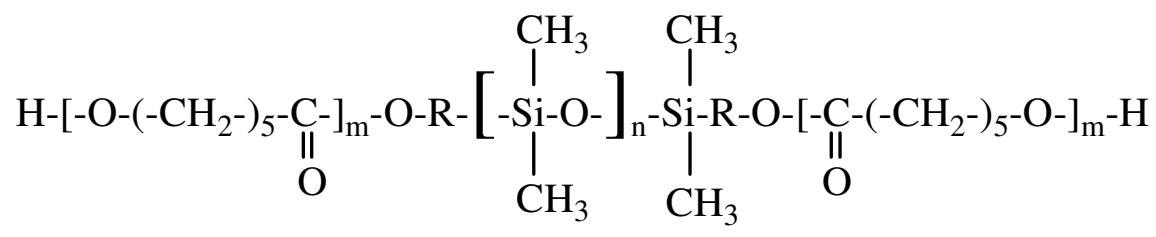

where $n=30$ (i.e. $M[P D M S] \approx 2200$ ) and $m=9$ (i.e. $M[P C L] \approx 1000$ at each end, referred to as "PDMS$P C L 1000$ " or $m=27$ (i.e. $M[P C L] \approx 3000$ at each end, referred to as "PDMS-PCL3000", and $R$ is an aliphatic radical.

\section{RESULTS AND DISCUSSION}

\section{Main reactions involved}

Model kinetic studies were at first conducted on stoichiometric $(\mathrm{OCN} / \mathrm{OH}=1) \mathrm{DCBA} / \mathrm{P}_{2} \mathrm{E}$ mixtures. In situ FTIR experiments (Fig. 1) at $150^{\circ} \mathrm{C}$ allowed to monitor the disappearance of cyanate and alcohol functions, and revealed that part of the latter were transformed into phenol functions. The iminocarbonate peak $\left(1675 \mathrm{~cm}^{-1}\right)$ was instantaneously detected, as well as cyanate cyclotrimerization 
leading to triazine rings $\left(1565 \mathrm{~cm}^{-1}\right)$. In the meanwhile, size exclusion chromatography (SEC) measurements showed that $\mathrm{P}_{2} E$ molecules were consumed very slowly and that their conversion seemed to reach a plateau, while the consumption of dicyanate molecules soon reached completion. These various observations suggest that the following reactions could be involved (scheme 1): in the first stages, the iminocarbonate adduct $P_{2} E / D C B A$ would be formed and would induce cyanate trimerization according to the generally admitted mechanism (Ref. 5). Grigat (Ref. 2) and Alla (Ref. 6) observed that the most acidic phenol was released and thus a substituted triazine ring should be obtained with the liberation of a monophenol deriving from DCBA. At this stage, sufficient amounts of the classical cyanate cyclotrimerization catalyst [i.e. phenol, (Ref. 5)] should have been formed and this reaction could go on much faster than that involving $\mathrm{P}_{2} \mathrm{E}$.

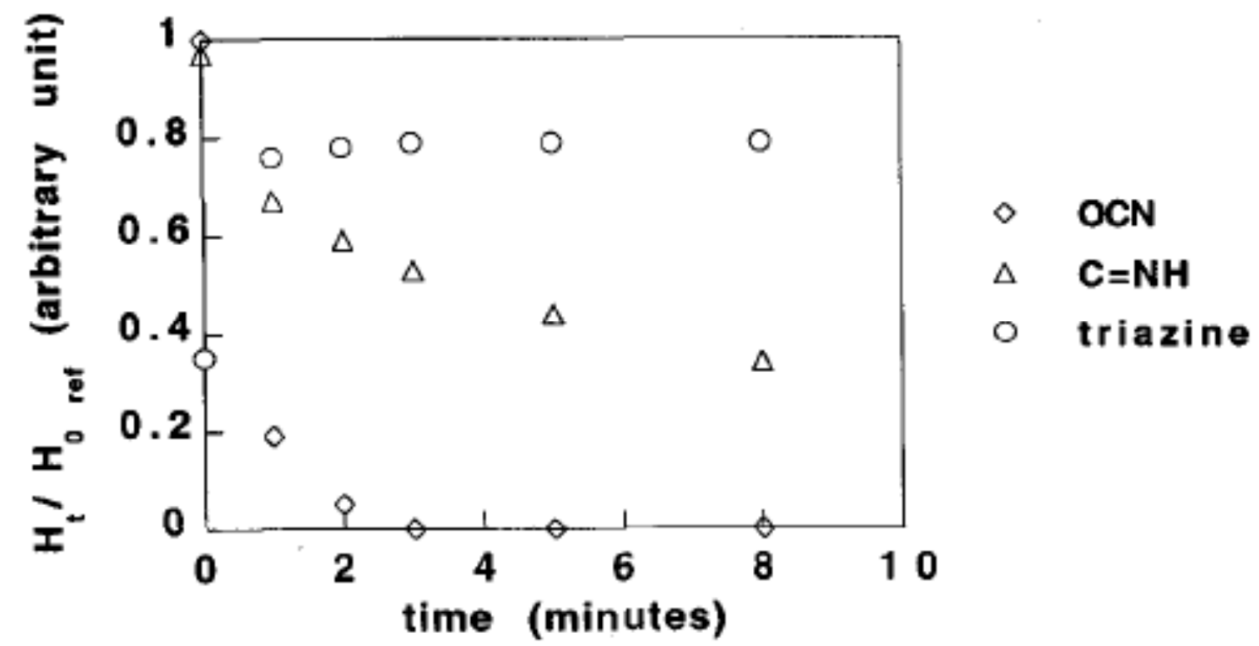

Fig. 1. Evolution of FTIR characteristic peaks (peak heights are normalized)

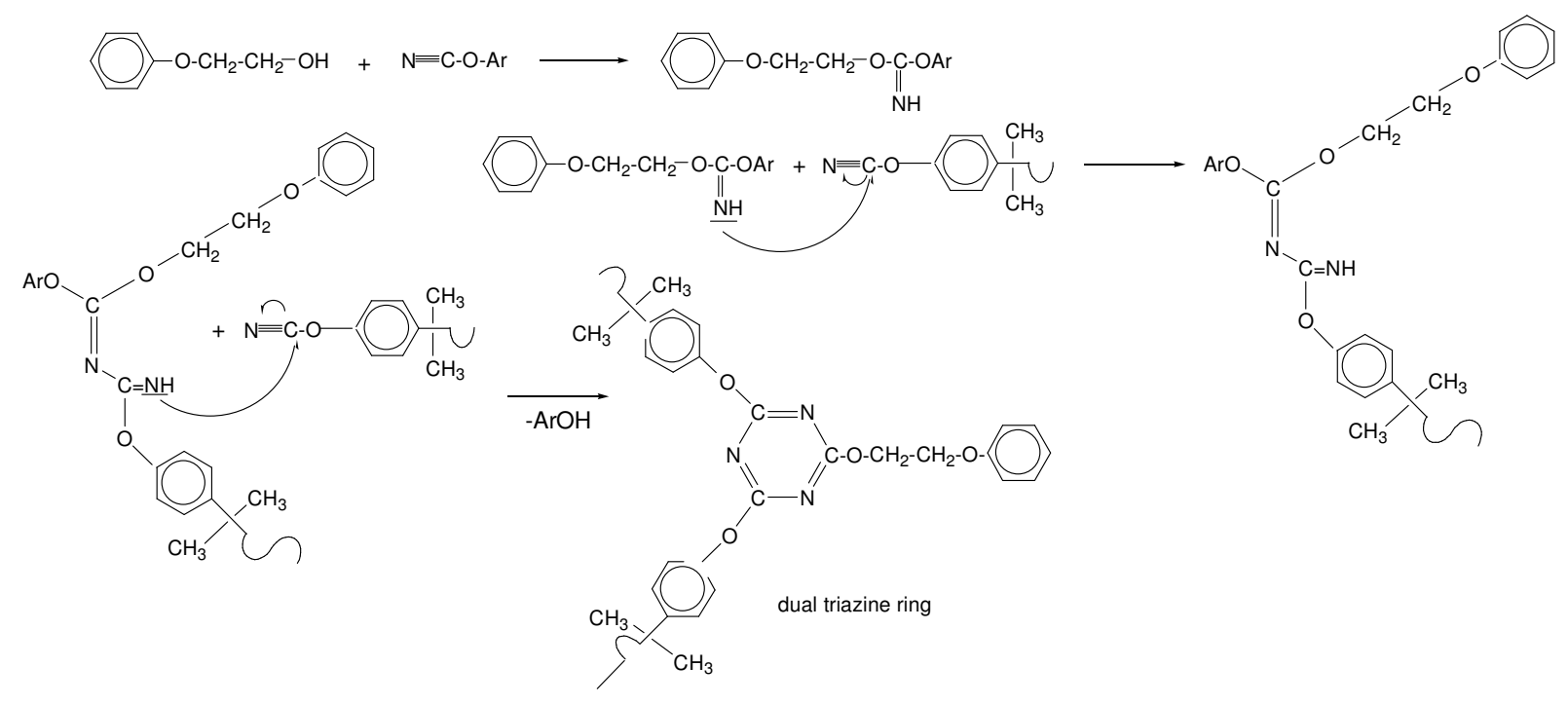

Scheme 1. Possible reactions in the presence of aliphatic alcohols 
The same behavior was found for the dihydroxy-terminated triblock copolymers. Moreover, UV detection during SEC measurements revealed that the non-absorbing $(\lambda=254 \mathrm{~nm})$ initial chains were changed into strongly absorbing ones, confirming that the copolymer was now partially chemically linked to the polycyanurate growing network through dual triazine rings. Alcohol functions were in the same time partially changed into phenol functions.

\section{Microcalorimetric and dynamic mechanical studies}

Differential scanning calorimetry (DSC) performed at $10 \mathrm{~K} / \mathrm{min}$ on mixtures of DCBE with various amounts of PDMS-PCL(1000 or 3000) showed that a single exotherm was observed, with a reaction enthalpy roughly independent of the relative amount of hydroxyl groups : $\Delta \mathrm{H} \approx 100 \mathrm{~kJ} / \mathrm{mol} O C N$, i.e. close to the value found for the polycyclotrimerization of pure DCBE, $102 \mathrm{~kJ} / \mathrm{mol}$ OCN (Ref. 7). However the temperature at the exotherm maximum $T_{\max }$ is strongly influenced by the amount of triblock copolymer. More precisely, we observed by comparing the results obtained with both additives that $\mathrm{T}_{\max }$ was only determined by the $\mathrm{OCN} / \mathrm{OH}$ ratio :

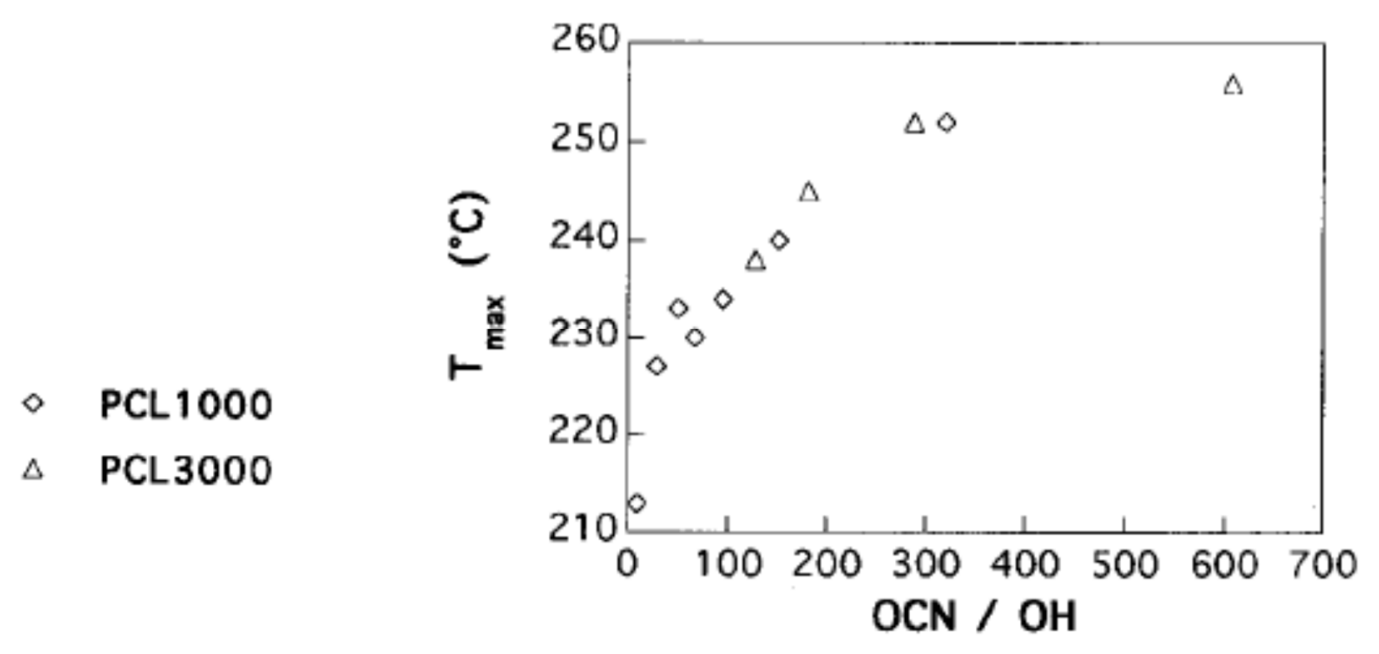

Fig. 2. DSC exotherm maximum for various DCBE/PDMS-PCL mixtures

This confirms that the triblock copolymers activate polycyclotrimerization through their hydroxyl endgroups, whereas there is no effect of the chain itself. $T_{\max }$ increases with $\mathrm{OCN} / \mathrm{OH}$, until it nears the value associated with pure DCBE $\left[290^{\circ} \mathrm{C}\right.$, (Ref. 7)].

A second DSC scan performed on the same samples allowed the investigation of their thermal properties. Although some materials are soft (low amounts of PDMS-b-PCL) while others are more rigid (higher amounts), a glass transition at high temperature $\left(T_{g h}\right)$ is always detected, suggesting that a phase separation probably occurs during polycondensation. Increasing amounts of additive lead at first to decreasing ultimate $T_{g h}$ 'S. PDMS is not miscible with DCBE nor with DCBA, contrary to PCL which can thus be partially responsible for this plasticization. However for low amounts of modifier (up to $20 \mathrm{wt} \%$ ), the addition of PDMS-PCL3000 induces a lower decrease in the final $\mathrm{T}_{\mathrm{gh}}$ than an equal amount of PCL brought by PDMS-PCL1000. The difference can be explained by the presence of more hydroxyl functions in the latter case, which result in numerous dangling or linear chains in the polycyanurate network and contribute to its plasticization (Ref. 7). 
The plot of $T_{g h}$ vs. the amount of PDMS (wt.-\%) for both modifiers is a unique curve; $T_{g h}$ is found to decrease and then increase again almost linearly with increasing amounts of PDMS. The reason for this minimum value (around 10 wt.-\% PDMS) is difficult to assess (phase inversion, new phase separation ?...). Therefore, the dynamic mechanical properties of the materials obtained by pre-curing at $180-200^{\circ} \mathrm{C}$ and post curing at $230^{\circ} \mathrm{C}$ were examined. In fact, the temperature corresponding to the maximum in $\tan \delta$ follows a specific tendency (Fig. 3): an anomalous phenomenon occurs for 10 wt.-\% PDMS, which could correspond to a change in the morphology. Meanwhile, the rubbery modulus $\mathrm{G}_{c}$ measured at $T_{\alpha}+40^{\circ} \mathrm{C}$ is not really affected $\left(G_{c}=10-20 \mathrm{MPa}\right.$ over the whole range of PDMS amount) which makes the phase inversion hypothesis rather doubtful.

Finally at low temperature, the $\alpha$ transition of pure PDMS is clearly visible for samples based on PCL1000, confirming the presence of a separated PDMS phase; in contrast, it can't be detected for PCL3000 and it is not possible to determine whether this relaxation overlaps with the $\gamma$ relaxation of the polycyanurate network or does not exist at all in this case.

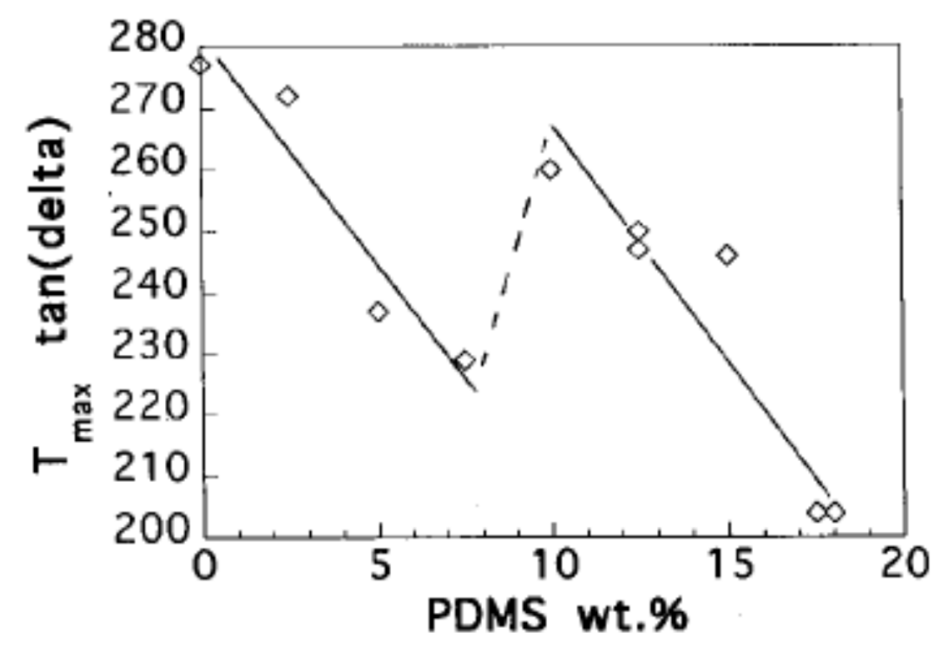

Fig. 3. Mechanical transition associated with $T_{g h}$ as a function of PDMS wt.-\%

\section{Morphology and mechanical properties}

- A first series of materials were prepared from DCBE modified by 5, 10, 15 or $20 \mathrm{wt} \%$ of PDMS-PCL1000 or 3000 . All samples looked homogeneous by EDS Si mapping (depth analyzed $\approx 2 \mu \mathrm{m}$ ), and no marked difference appeared on SEM micrographs when comparing the materials obtained with equal amounts of either additive. On the contrary, various amounts of PDMS-PCL1000 led to different surface aspects: with lower amounts (up to 15 wt.-\% additive, i.e. 7.5 wt.-\% PDMS), small dispersed particles could be seen (diameter : 0.2-0.4 $\mu \mathrm{m}$ ) whereas they were too small to be detectable with the highest amount (20 wt.-\% triblock copolymer, i.e. precisely the critical value of $10 \mathrm{wt} .-\%$ PDMS). A possible explanation, together with the increasing PCL/DCBE and PDMS/DCBE ratios, could be that higher and higher amounts of additive brought relatively higher and higher proportions of hydroxyl functions and consequently polymerization proceeded faster and faster. Rozenberg (Ref. 9) indeed showed that for a given phase-separating system, increasing amounts of catalyst could lead to a dispersed phase of decreasing average size. 
- In another series of experiments, $10 \mathrm{wt} \%$ PDMS-PCL1000 were hand-mixed with pure or partially converted DCBA (initial conversion $x_{0}=0,0.28$ and 0.47 ). The three networks were cured following a usual procedure (Refs. 3,4 ) and the morphologies were examined by scanning electron microscopy (SEM) with the help of EDS X-ray microanalysis. The materials obtained with $\mathrm{x}_{0}=0$ or 0.28 display a very finely divided morphology since they look homogeneous at the SEM definition level ( $0.1 \mu \mathrm{m})$ as well as considering the depth analyzed by $\operatorname{EDX}(2-3 \mu \mathrm{m})$. This is not surprising since Könczöl et al claim a mean diameter of $20 \mathrm{~nm}$ for the dispersed phase in the case of polyepoxy networks (Ref. 8). However when $\mathrm{x}_{0}=0.47$, much larger (mean diameter $=9 \mu \mathrm{m}$ ) and very diffuse dispersed particles are observed; an EDS Si map reveals that these particles are rich in silicon and thus probably contain a large amount of PDMS. One may think that the miscibility between PDMS-PCL1000 and the growing polycyanurate network decreases with increasing conversion; if so, the first two systems could be initially homogeneous and as polycyclotrimerization proceeds would first undergo phase separation and then gelation, hence the tiny size of the particles. On the contrary, the sample with $\mathrm{x}_{0}=0.47$ could be beyond phase separation from the start and as it is also very close to gelation $\left(x_{\mathrm{gel}} \approx 0.55\right)$ the observed morphology could reflect the degree of heterogeneity obtained by hand-mixing. However further studies (particularly the knowledge of the phase diagram and of the morphology evolution after gelation) would be necessary to support these hypotheses. The very diffuse aspect of the dispersed phase (which seems to display a complex substructure) results from the chemical links between matrix and additive, which can create a kind of broad interphase, and/or from a partial miscibility.

Thanks to this special morphology with highly interpenetrated phases, the static mechanical properties, and especially the critical stress intensity factor $\mathrm{K}_{1 \mathrm{c}}$ were greatly improved by the addition of as low as $5 \mathrm{wt} \%$ additive. In fact, this low amount is sufficient to increase $\mathrm{K}_{1 \mathrm{c}}$ from 0.6 to $1.2 \mathrm{MPa} \sqrt{\mathrm{m}}$ and no real further increase was observed with higher amounts of modifier.

\section{CONCLUSION}

The modification of polycyanurate networks by additives bearing alcohol functions is specially interesting since they provide chemical links between matrix and modifier. The use of PCL-b-PDMS-bPCL triblock copolymers led to heterogeneous materials, with finely divided morphologies highly dependent on the modifier amount and on the initial cyanate conversion.

\section{REFERENCES}

(1) "Chemistry and Technology of Cyanate Ester Resins ", I. Hamerton, Ed., Blackie Academic \& Professional, Glasgow, 1994 and references therein.

(2) E. GRIGAT, R. PUTTER, Angew. Chem. Int. Ed. 6, 206 (1967).

(3) Z.Q. CAO, PhD Thesis, INSA Lyon (1994).

(4) Z.Q.CAO, F. MECHIN, J.P. PASCAULT, Polym. Int. 34, 41 (1994).

(5) M. BAUER, J. BAUER, G. KUHN Acta Polym. 37, 715 (1986).

(6) C. ALLA, PhD Thesis, University of Paris VI (1992).

(7) V. MIRCO, PhD Thesis, INSA Lyon (1995).

(8) L. KÖNCZÖL, W. DÖLL, U. BUCHHOLZ, R. MÜLHAUPT, J. Appl. Polym. Sci. 54, 815 (1994).

(9) B.A. ROZENBERG, Makromol. Chem. Macromol. Svmp. 41, 165 (1991). 